\title{
A Bleeding Liver Tumor
}

\section{Case Report}

T.M. van Gulik

Department of Surgery, Academic Medical Center, University of Amsterdam, The Netherlands

\section{Key Words}

Liver tumor - Liver bleed · Hepatocellular adenoma . Liver resection $\cdot$ Abdominal packing

\section{Case Report}

Clinical presentation: A 33-year-old female patient presented with acute, abdominal right upper-quadrant pain, referred to the right shoulder. She had not vomited and her stools were normal. Her previous history was unremarkable. She had been taking oral contraceptives for the past 10 years, but otherwise had no medication.

Physical examination: Her pulse rate was raised, but temperature and blood pressure were normal. Both upper abdominal quadrants were painful on palpation, but there was no abdominal rigidity or tenderness. Liver dullness was present on percussion.

Laboratory tests: The laboratory results showed slightly abnormal liver function tests (AST $40 \mathrm{U} / 1$, alkaline phosphatase $100 \mathrm{U} / 1, \gamma$-GT $60 \mathrm{U} / \mathrm{l})$. The hemoglobin content of the blood was below normal $(5.2 \mathrm{mmol} / \mathrm{l})$, with normal coagulation parameters. The leukocyte count was elevated $\left(11 \times 10^{9} / 1\right)$ while serum amylase was normal.

\section{Question 1}

What is the presumptive diagnosis?
A Peptic ulcer perforation
B Biliary colic
C Bleed from liver tumor
D Acute pancreatitis

Audience's response

$23 \%$

$57 \%$

$9 \%$

$11 \%$

\section{Commentary}

The more common causes of acute upper abdominal pain usually relate to peptic ulcer disease or to biliary colic due to gallstones. Acute pancreatitis is also not an uncommon finding in patients with acute upper abdominal pain. Bleeding from a liver tumor is a relatively rare condition in Western Europe. In South-East Asia, however, where hepatocellular carcinoma (HCC) is more frequent, bleeding and spontaneous rupture of the liver is a common presentation of HCC. The incidence of this potentially lifethreatening complication of HCC varies from 2.9 to $26 \%$ [1]. In Western Europe, a bleed in the liver may equally be associated with a hepatocellular adenoma, especially when occurring in middle-aged women.

\section{Case Report (Continued)}

Abdominal ultrasound examination was performed, showing a lesion in the right liver. Subsequent multiphasic, helical CT scan showed a well-delineated mass in the right liver (segments 6 and 7), measuring $7 \mathrm{~cm}$, in conjunction with a subcapsular hematoma (fig. 1).

\section{Question 2}

What is the most likely diagnosis?
A Bleed from hepatocellular carcinoma
B Bleed from hepatocellular adenoma $27 \%$
C Bleed from hemangioma
$46 \%$
D Bleed in biliary cyst

Audience's response

\begin{tabular}{ll}
\hline KARGER & ○ 2002 S. Karger AG, Basel \\
Fax +41 61 306 12 34 & 0253-4886/02/0192-0106\$18.50/0 \\
$\begin{array}{l}\text { E-Mail karger@karger.ch } \\
\text { www.karger.com }\end{array}$ & $\begin{array}{l}\text { Accessible online at: } \\
\text { www.karger.com/journals/dsu }\end{array}$
\end{tabular}

\footnotetext{
Thomas M. van Gulik

Department of Surgery, Academic Medical Center, University of Amsterdam 9 Meibergdreef

NL-1105 AZ Amsterdam (The Netherlands)

Tel./Fax+31206914858, E-Mail t.m.vangulik@amc.uva.nl
} 


\section{Commentary}

The correct answer is B. Clinical presentation and imaging studies fit with a bleed from a liver tumor. The CT image is composed of hypo- and hyperdense areas corresponding with a recent bleed in which clots and blood coexist. Although a frank tumor could not be defined amongst the clots, the diagnosis in all probability was a ruptured tumor that had resulted in a parenchymal hemorrhage. The bleed had propagated itself as a subcapsular hematoma. There were no signs of a hemoperitoneum at the time of the CT scan. In this young woman who was taking oral contraceptives for many years, the diagnosis most likely was an intrahepatic bleed due to a contained rupture of a hepatocellular adenoma. Liver hemangiomas rarely bleed, unless the liver is traumatized. Bleeding complications of biliary cysts are also very rare.

\section{Question 3}

What would you do as initial treatment?

\section{A Conservative treatment/observation}

B Angiography and embolization hepatic artery

C Laparotomy and packing

D Laparotomy and resection
Audience's response $44 \%$
Because the patient was hemodynamically stable, she was treated conservatively (A), i.e. with an intravenous drip and close observation.

\section{Case Report (Continued)}

On the third day after admission, the patient went into hypovolemic shock with signs of intra-abdominal bleeding. Ultrasound showed massive fluid in the abdomen.

\section{Question 4}

Treatment now consists of?

Audience's response

A Angiography and embolization of hepatic artery

B Laparotomy and tying of hepatic artery

C Laparotomy and packing

D Laparotomy and resection

\section{Case Report (Continued)}

An emergency laparotomy was performed revealing a massive bleed from the right liver. To control the bleeding, the liver was gauze packed and the abdomen closed (C). This procedure was successful in arresting blood loss after which the patient stabilized. The patient was referred to a specialized center the next day.

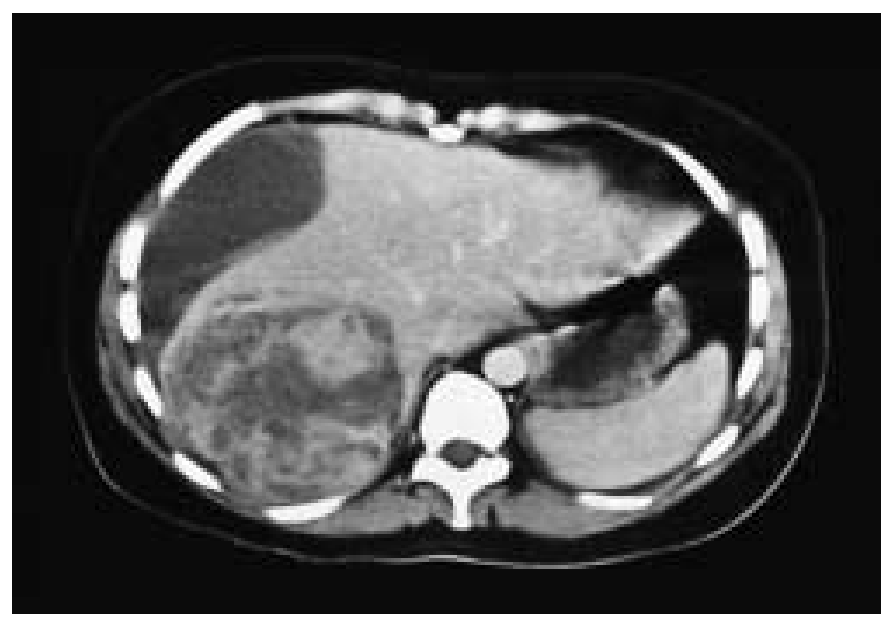

Fig. 1. CT scan showed a well-delineated mass in the right liver in conjunction with a subcapsular hematoma.

\section{Commentary}

The goal of initial treatment of patients with a ruptured hepatocellular adenoma consists of hemodynamic stabilization. The most simple and effective method to control bleeding is gauze packing at laparotomy. This procedure can be performed on an emergency basis in any hospital, and does not necessarily require specific experience with liver surgery. Embolization of the (right or left) hepatic artery has proven effective in stopping bleeding from a ruptured HCC [2] and is applicable to ruptured hepatocellular adenoma too. An emergency liver resection for bleeding is associated with high morbidity and mortality and should only be considered in experienced centers.

\section{Question 5}

What is the next step in the treatment of this patient?

A Perform hepatic artery embolization and remove packs Audience's response

B Remove packs and tie hepatic artery

C Remove packs and perform resection

D Remove packs and delay resection

\section{Commentary}

The packs were removed on the second day; resection of the tumor was delayed (D). Delayed resections for ruptured liver tumors are considered safer than (semi)acute resections. 


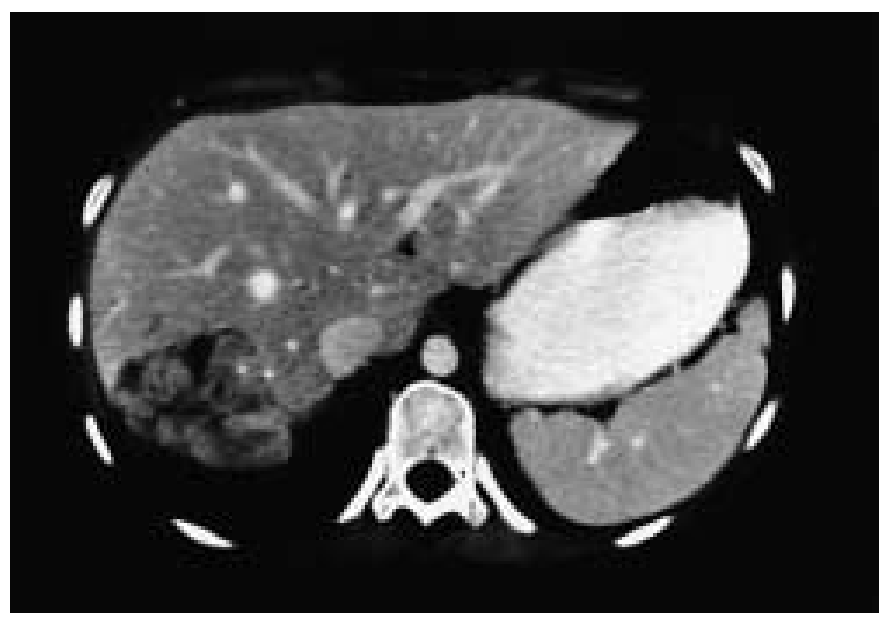

Fig. 2. CT scan 2 months after packing of the liver bleed showing a persisting mass in the right liver.

\section{Case Report (Continued)}

Two months following laparotomy, a repeat CT scan was performed showing a persisting mass in the right liver, consistent with the site of the previous bleed (fig. 2). The subcapsular hematoma had resolved.

\section{Question 6}

What is the final treatment?

A Observe, no further treatment necessary

Audience's response

B First obtain tissue diagnosis (core biopsy) $5 \%$

C Perform resection $23 \%$

D Perform US-guided, percutaneous radiofrequency ablation
Case Report (Continued)

A right hemihepatectomy was eventually performed with uneventful postoperative course (C). On microscopical examination of the resection specimen, differentiation between hepatocellular adenoma or (well-differentiated) carcinoma could not be established due to extensive, postnecrotic scarring at the site of the previous bleeding. The patient, however, is doing well now more than 6 years after.

\section{Conclusion}

Hepatocellular adenomas are relatively rare, benign liver tumors usually occurring in young women (mean age 35 years) and are often associated with the use of oral contraceptives. Spontaneous bleeding of hepatocellular adenoma may give rise to serious complications, especially when rupture into the abdomen has occurred. Initial treatment should be directed to hemodynamic stabilization of the patient and can be effectively achieved by laparotomy and gauze packing. Delayed partial liver resection is recommended. Preventive resection is advised for hepatocellular adenomas of $5 \mathrm{~cm}$ or larger because of the risk of malignant degeneration and bleeding.

Although this case rather is a description of an intrinsic complication of a liver tumor, massive intra-abdominal bleeding may necessitate emergency laparotomy and lead to intra- or postoperative complications with which any surgeon can be confronted.

\section{References}

1 Chen CY, Lin XZ, Shin JS, et al: Spontaneous rupture of hepatocellular carcinoma. A review of 141 Taiwanese cases and comparison with non-ruptured cases. J Clin Gastroenterol 1995; 21:238-242.

2 Ngan H, Tso WK, Lai CL, Fan ST: The role of hepatic arterial embolization in the treatment of spontaneous rupture of hepatocellular carcinoma. Clin Radiol 1998;53:338-341. 